\title{
Association of PTPN22 single nucleotide polymorphism with rheumatoid arthritis but not with allergic asthma
}

Edyta Majorczyk ${ }^{1}$, Monika Jasek ${ }^{1}$, Rafał Płoski ${ }^{2}$, Marta Wagner ${ }^{1}$, Anna Kosior ${ }^{1}$, Andrzej Pawlik ${ }^{3}$, Andrzej Obojski ${ }^{4}$, Wioleta Łuszczek $^{1}$, Izabela Nowak ${ }^{1}$, Andrzej Wiśniewski ${ }^{1}$ and Piotr Kuśnierczyk ${ }^{*, 1,5}$

\footnotetext{
${ }^{1}$ Laboratory of Immunogenetics, Department of Clinical Immunology, Ludwik Hirszfeld Institute of Immunology and Experimental Therapy, Polish Academy of Sciences, Wrocław, Poland; ${ }^{2}$ Department of Medical Genetics, Medical University of Warsaw, Warsaw, Poland; ${ }^{3}$ Department of Pharmacokinetics and Therapeutic Drug Monitoring, Pomeranian University of Medicine, Szczecin, Poland; ${ }^{4}$ Department of Internal Medicine and Allergology, Clinic of Internal Diseases and Allergology, Wrocław Medical University, Wrocław, Poland; ${ }^{5}$ Department of Microbiology and Biotechnology, Institute of Chemistry and Environmental Protection, Jan Długosz Pedagogical University, Częstochowa, Poland
}

PTPN22 gene encodes a lymphoid tyrosine phosphatase (LYP), an important negative regulator of T-cell responses. The 1858C $>$ T (Arg620Trp) single nucleotide polymorphism (rs2476601) was found associated with autoimmune diseases, including rheumatoid arthritis (RA). Allergic diseases are similar to autoimmune diseases, by an exaggerated immune response to an antigen (allergen in this case) normally not invoking such response in healthy individuals. We investigated whether polymorphism 1858C $>$ T in PTPN22 gene is associated with susceptibility to allergic asthma and RA in a Polish population. PTPN22 was genotyped in 173 patients with RA, in 198 patients with allergic asthma, and in 543 controls using PCR-RFLP. The patients with RA differed from healthy controls in frequencies of $P$ TPN22 1858C $>$ T alleles $(P=0.0004$; odds ratio $(O R), 1.8$; 95\% Cl, 1.33-2.55) and genotypes $(P=0.0009)$. Strong associations of $1858 \mathrm{~T}$ allele with RA limited to joints (0.21 vs $0.12, P=0.0002 ; \mathrm{OR}, 2.1 ; 95 \% \mathrm{Cl}, 1.44-3.00)$, with erosive disease $(0.20$ vs $0.12, P=0.0003 ; 0 R, 1.92$; $95 \% \mathrm{Cl}, 1.34-2.71$ ), with a lack of rheumatoid factor (RF; 0.23 vs $0.12, P=0.0008 ; \mathrm{OR}, 2.29 ; 95 \% \mathrm{Cl}$, 1.44-3.63), and weak association with the presence of $\operatorname{RF}(0.17$ vs $0.12, P=0.02 ; \mathrm{OR}, 1.6 ; 95 \% \mathrm{Cl}, 1.10-2.40)$ in comparison with healthy controls were observed. Very strong association of $1858 \mathrm{~T}$ allele $(P<0.0001 ; O R$, $2.72 ; 95 \% \mathrm{Cl}, 1.9-3.9)$ and $\mathrm{T}$ phenotype $(P<0001 ; \mathrm{OR}, 3.2 ; 95 \% \mathrm{Cl}, 2.1-4.9)$ with antibodies to cyclic citrullinated peptide (CCP) was found. When patients with allergic asthma were typed for PTPN22 1858C $>$ T polymorphism, no difference with control was found. Subdivision of patients into those with mild, moderate, or severe asthma did not reveal any associations. In conclusion, we confirmed associations between several clinical manifestations of RA and PTPN22 1858T allele. However, no association with 1858C $>$ T polymorphism was found for susceptibility to allergic asthma or for severity of the disease.

European Journal of Human Genetics (2007) 15, 1043-1048; doi:10.1038/sj.ejhg.5201879; published online 20 June 2007

Keywords: PTPN22 gene; single nucleotide polymorphism; rheumatoid arthritis; allergic asthma

*Correspondence: Professor P Kuśnierczyk, Laboratory of Immunogenetics, Department of Clinical Immunology, Ludwik Hirszfeld Institute of Immunology and Experimental Therapy, Polish Academy of Sciences, ul. Rudolfa Weigla 12, PL-53-114 Wroclaw, Poland. Tel: + 4871370 9976; Fax: + 4871337 1382; E-mail: pkusnier@iitd.pan.wroc.pl Received 1 March 2007; revised 18 May 2007; accepted 18 May 2007; published online 20 June 2007
Introduction

Lymphoid tyrosine phosphatase (LYP) encoded by PTPN22 is an intracellular enzyme that dephosphorylates Src family kinases Lck and Fyn as well as components of the TCR/CD3 complex and other key signaling molecules. ${ }^{1,2}$ Therefore, 
LYP appears to be an important negative regulator of T-cell responses.

Recently, Bottini et $\mathrm{al}^{3}$ described a single nucleotide polymorphism (SNP) in PTPN22 gene, 1858C > T, changing arginine to tryptophan residue in position 620 of mature protein. The $1858 \mathrm{~T}(620 \mathrm{~W})$ variant was found associated with insulin-dependent diabetes mellitus. ${ }^{3}$ Subsequently, association with $1858 \mathrm{~T}$ was reproducibly described for other autoimmune diseases, including rheumatoid arthritis (RA). ${ }^{2}$ Interestingly, a general view emerged that $1858 \mathrm{~T}$ variant is associated mostly with these autoimmune diseases, which exhibit a prominent contribution of autoantibodies. In contrast, association with $1858 \mathrm{~T}$ could not be detected in autoimmune diseases where autoantibodies do not seem to play any role. $^{2}$

In $\mathrm{RA}$, associations with $1858 \mathrm{C}>\mathrm{T}$ were studied in several clinical manifestations, including a presence of rheumatoid factor (RF), anti-cyclic citrullinated peptide (aCCP) antibodies, erosive disease (ED), and extra-articular manifestations. ${ }^{2,4-8}$ However, a disease limited to joints $v s$ RA with extra-articular complications was compared only in one study undertaken for a Spanish population, ${ }^{7}$ which is genetically somewhat distant from Poles (eg, PTPN22 $1858 \mathrm{C}>\mathrm{T}$ frequencies are significantly different; $P<0.0001$ for difference in allele and genotype frequencies between Spaniards ${ }^{7,9}$ and Poles (this report)). Therefore, we tested all clinical manifestations of RA mentioned above for distribution of $1858 \mathrm{C}>\mathrm{T}$ SNP in Polish patients.

In autoimmune diseases, a harmful response to selfantigen(s) normally not invoking such reaction in healthy individuals is the etiological factor. Similarly, in allergic diseases, an exaggerated immune response to an 'innocent' antigen (allergen in this case) is observed. In addition, antibodies (of the IgE class) play important role in their pathogenesis, and several other effector pathways seem to contribute to both autoimmune and allergic pathology. ${ }^{10}$ Thus, it seemed conceivable that PTPN22 polymorphism might play a role in allergic diseases as well. However, no such studies in allergy have been published so far. Therefore, in addition to the RA study, we compared here for the first time the distribution of $1858 \mathrm{C}>\mathrm{T}$ alleles and genotypes in patients with allergic asthma and healthy control individuals.

\section{Materials and methods Study populations}

A case-control association study was performed to examine whether the PTPN22 1858C > T missense (R620W) SNP was associated with different clinical manifestations of RA and allergic asthma.

One hundred and seventy-three patients (140 women and 33 men, age $57.9 \pm 12.5$ years, range $22-83$ years) with RA diagnosed as described by Pawlik et al, ${ }^{11}$ according to the criteria of the American College of Rheumatology, were enrolled into the study. Patients were recruited from the inpatient and outpatient population of the Department of Rheumatology, Autonomous Public Clinical Hospital No. 1 of the Pomeranian Medical University in Szczecin, Poland. Stratification analysis was performed on the RA cohort to investigate the effect of age, age at disease diagnosis, disease duration, presence of RF and aCCP antibodies, and $\mathrm{ED}$, and limitation of disease to joints $v s$ extra-articular manifestations such as vasculitis, pulmonary fibrosis, and Sjögren syndrome. Clinical characteristics of the patients are given in Table 1a.

One hundred and ninety-eight patients $(40.7 \pm 16.5$ years, range 6-98) were diagnosed with allergic asthma

Table 1 Characteristics of patient groups

\begin{tabular}{lccrc}
\hline Characteristics & $\begin{array}{c}\mathrm{N} \\
\text { (females/males) }\end{array}$ & $\begin{array}{c}\text { Age } \\
\text { (years } \pm \text { SD, range) }\end{array}$ & $\begin{array}{c}\text { Disease duration } \\
\text { (years } \pm S D, \text { range) }\end{array}$ & $\begin{array}{c}\text { Age at onset } \\
\text { (years } \pm S D, \text { range) }\end{array}$ \\
\hline $\begin{array}{l}\text { (a) Rheumatoid arthritis } \\
\text { All cases }\end{array}$ & $173(140 / 33)$ & $57.9 \pm 12.5,22-83$ & $10.8 \pm 8.5,1-50$ & $47.0 \pm 13.3,13-77$ \\
RA limited to the joints & $115(93 / 22)$ & $57.9 \pm 12.3,22-83$ & $11.0 \pm 8.5,1-50$ & $46.8 \pm 13.5,14-74$ \\
RA with extra-articular & $58(47 / 11)$ & $57.8 \pm 13.0,35-80$ & $10.3 \pm 8.6,1-39$ & $47.5 \pm 13.0,13-77$ \\
manifestations & & & & \\
RA RF+ & $112(93 / 19)$ & $57.6 \pm 11.8,22-79$ & $11.6 \pm 9.3,1-50$ & $45.9 \pm 12.8,13-77$ \\
RA RF- & $61(47 / 14)$ & $58.4 \pm 13.9,28-83$ & $9.1 \pm 6.6,1-30$ & $49.1 \pm 14.0,14-74$ \\
RA anti-CCP+ & $107(91 / 16)$ & $59.0 \pm 12.7,22-83$ & $11.6 \pm 9.1,1-50$ & $47.3 \pm 12.8,14-74$ \\
RA anti-CCP- & $52(36 / 16)$ & $57.4 \pm 12.3,29-80$ & $9.3 \pm 7.5,1-35$ & $48.1 \pm 14.6,13-77$ \\
RA ED+ & $145(117 / 28)$ & $58.3 \pm 12.2,28-83$ & $12.2 \pm 8.4,1-50$ & $46.0 \pm 12.9,13-74$ \\
RA ED- & $28(23 / 5)$ & $55.6 \pm 14.0,22-79$ & $3.2 \pm 3.3,1-17$ & $52.4 \pm 14.0,21-77$ \\
& & & & \\
(b) Allergic asthma & $198(124 / 74)$ & $40.7 \pm 16.5,6-98$ & $15.3 \pm 12.1,0-71$ & $25.6 \pm 15.7,1-69$ \\
All cases & $54(31 / 23)$ & $34.6 \pm 19.4,13-98$ & $11.8 \pm 10.1,0-57$ & $23.2 \pm 15.0,2-57$ \\
Asthma I & $52(28 / 24)$ & $39.3 \pm 14.3,13-63$ & $9.2 \pm 8.4,0-32$ & $30.1 \pm 15.5,4-57$ \\
Asthma II & $106(59 / 47)$ & $37.0 \pm 17.1,13-98$ & $10.5 \pm 9.3,0-57$ & $26.6 \pm 15.6,2-57$ \\
Asthma I+ll & $92(65 / 27)$ & $45.4 \pm 14.6,6-78$ & $21.1 \pm 12.7,0-71$ & $24.3 \pm 15.8,1-69$ \\
Asthma III & & & & \\
\hline
\end{tabular}


according to NHLBI/WHO guidelines ${ }^{12}$ and evidenced to be atopic as described. ${ }^{13}$ The patients were subdivided according to NHLBI/WHO guidelines into three subgroups: asthma I, mild asthma (54 individuals); asthma II, moderate asthma (52 individuals); and asthma III, severe asthma (92 individuals). Characteristics of the patients are shown in Table $1 \mathrm{~b}$.

Five hundred and forty-three unrelated healthy volunteers, ethnically matched, were considered for the control. Two hundred and thirty-three volunteers were recruited in Wrocław (mean age, 32.4 \pm 10.7 years, range $14-77$ years; 103 women, 127 men, and 3 unknown). Three hundred and ten individuals were described elsewhere; ${ }^{14}$ these persons (155 women and 155 men) were picked from paternity testing, and therefore their personal data, including age, must have been anonymous to obtain permission from the Local Ethical Committee.

The project was approved by the Ethical Committees of the Pomeranian Medical University in Szczecin, Wrocław Medical University, and Medical University of Warsaw. Signed informed consent was obtained from all tested subjects, including parents in the case of juveniles.

\section{DNA isolation and PTPN22 typing}

Genomic DNA was extracted from peripheral blood leukocytes using methods described earlier. ${ }^{13-15}$ PTPN22 $1858 \mathrm{C}>\mathrm{T}$ polymorphism was genotyped by RFLP-PCR using primers described by Bottini et al. ${ }^{3}$ Two hundred and thirty-three control individuals from Wrocław and all patients were typed as follows: a fragment of PTPN22 gene was amplified by PCR in a $20 \mu$ l total volume reaction containing $200 \mathrm{ng}$ genomic DNA, $2.5 \mathrm{mM} \mathrm{MgCl}_{2}, 1 \times \mathrm{PCR}$ buffer, $0.1 \mu \mathrm{M}$ of each primer, $0.25 \mathrm{mM}$ dNTPs, and $0.5 \mathrm{U}$ Taq polymerase (Invitrogen). The amplifications were performed under the following conditions: $95^{\circ} \mathrm{C}, 5 \mathrm{~min}$; 30 cycles of $30 \mathrm{~s}$ at $95^{\circ} \mathrm{C}, 30 \mathrm{~s}$ at $60^{\circ} \mathrm{C}$, and $30 \mathrm{~s}$ at $72^{\circ} \mathrm{C}$. The last elongation step was extended to $5 \mathrm{~min}$. The PCR product was digested using $0.4 \mathrm{U} \mathrm{XcmI}$ restriction enzyme (New England BioLabs) for $4 \mathrm{~h}$ at $37^{\circ} \mathrm{C}$. All digested products were electrophoresed on 3\% agarose. Three hundred and ten control individuals from Warsaw were typed in conditions as described. ${ }^{3}$

\section{Statistical analysis}

Frequencies of PTPN22 alleles were established by direct counting. Differences between controls, patients, and patient subgroups were estimated using two-tailed Fisher exact test and GraphPad InStat 3 software. For calculation of genotype frequencies, $\chi^{2}$-test and EpiInfo software were used.

\section{Results}

RA patients differed from healthy control individuals in frequencies of PTPN22 1858C $>$ T alleles $(P=0.0004)$ and genotypes $(P=0.0009)$, and the odds ratio $(\mathrm{OR})$ for the T allele was 1.8 (Table 2 ).

When we divided our patients according to the presence or absence of extra-articular complications, strong association of $1858 \mathrm{~T}$ allele with a disease limited to joints $(P=0.0002$ and 0.0003 for alleles and genotypes, respectively) was observed (OR for T allele, 2.08). Patients with extra-articular manifestations, including vasculitis, did not differ from control group (Table 2 and data not shown). Genotype frequencies in all groups were found to be in the Hardy-Weinberg equilibrium (not shown).

Next, we looked for PTPN22 1858C $>$ T association with RF. 1858 T allele was only weakly associated $(P=0.02)$ with seropositive RA but very strongly with seronegative RA $(P=0.0008 ; \mathrm{OR}=2.29$; Table 2$)$. Similarly, association of $1858 \mathrm{C}>\mathrm{T}$ genotypes with seronegative RA was much stronger than with seropositive RA. 1858T-positive phenotype (TT homozygotes plus CT heterozygotes) was highly significantly more frequent in RF-negative patients than in controls $(P=0.001)$, whereas its frequency in RF-positive patients was only weakly $(P=0.02)$ different from controls.

The presence of aCCP antibodies in RA patients was very strongly associated with $1858 \mathrm{~T}$ allele $(P<0.0001)$ and 1858 T carrier status $(P<0.0001$; Table 2$)$.

We also checked whether 1858C $>$ T SNP was associated with bone erosions in the joints (ED). Allele and genotype frequencies were highly significantly different from controls in patients with erosive disease $(P=0.0003$ and 0.0008 , respectively) but not in patients without bone erosions ( $P>0.05$ for alleles, genotypes, and $\mathrm{T}$ phenotype; Table 2). Association of $1858 \mathrm{~T}$ allele with erosive disease was much stronger in RF-negative patients $(P=0.0008$; OR, 2.5; 95\% CI, 1.5-4.3) than in RF-positive ones $(P=0.02$; OR, 1.6; 95\% CI, 1.1-2.5).

When patients with allergic asthma were typed for PTPN22 1858C $>\mathrm{T}$ polymorphism, no difference with control was found. Subdivision of patients into those with mild, moderate, or severe asthma did not reveal any associations (Table 3).

\section{Discussion}

We describe here our results on associations of $1858 \mathrm{C}>\mathrm{T}$ SNP with RA and allergic asthma. In RA, we confirm an association of $1858 \mathrm{~T}$ allele with susceptibility to this disease, with OR (1.8) similar to that described by others (range, 1.4-1.88). ${ }^{5-8,16,17}$ Moreover, a strong association of this SNP with erosive disease, described earlier in English population, ${ }^{6}$ was also found in our patients. Much weaker association of $1858 \mathrm{~T}$ with RA in patients without erosive disease, described by Hinks et al, ${ }^{6}$ did not reach statistical significance in our study because our sample was small in comparison to theirs. We also found a strong association of 1858T allele with RA limited to joints, whereas patients with extra-articular manifestations did not reveal such 
Table 2 PTPN22 1858C > T polymorphism in rheumatoid arthritis

\begin{tabular}{|c|c|c|c|c|c|c|c|c|c|c|}
\hline $\begin{array}{l}\text { (a) Allele an } \\
\text { PTPN22 } \\
1858 C>T\end{array}$ & $\begin{array}{l}\text { genotype fre } \\
\text { Controls } \\
(\mathrm{N}=543)\end{array}$ & $\begin{array}{l}\text { quencies } \\
\text { All cases } \\
(\mathrm{N}=173)\end{array}$ & $\begin{array}{l}\text { Limited to joints } \\
\qquad(\mathrm{N}=115)\end{array}$ & $\begin{array}{l}\text { Extra-articular } \\
\text { manifestation } \\
(\mathrm{N}=58)\end{array}$ & $\left(\begin{array}{c}R F+ \\
N=112)\end{array}\right.$ & $\begin{array}{c}R F- \\
(\mathrm{N}=61)\end{array}$ & $\begin{array}{l}\text { Anti-CCP+ } \\
(\mathrm{N}=107)\end{array}$ & $\begin{array}{l}\text { Anti-CCP- } \\
(\mathrm{N}=52)\end{array}$ & $\begin{array}{c}E D+ \\
(\mathrm{N}=145)\end{array}$ & $\begin{array}{c}E D- \\
(\mathrm{N}=28)\end{array}$ \\
\hline \multicolumn{11}{|l|}{ Alleles } \\
\hline C & $961(0.88)$ & $279(0.81)$ & $181(0.79)$ & $98(0.84)$ & $185(0.83)$ & $94(0.77)$ & $158(0.74)$ & $98(0.94)$ & $232(0.80)$ & $47(0.84)$ \\
\hline $\mathrm{T}$ & $125(0.12)$ & $67(0.19)$ & $49(0.21)$ & $18(0.16)$ & $39(0.17)$ & $28(0.23)$ & $56(0.26)$ & $6(0.06)$ & $58(0.20)$ & $9(0.16)$ \\
\hline \multicolumn{11}{|l|}{ Genotypes } \\
\hline $\mathrm{CC}^{\prime \prime}$ & $425(0.78)$ & $112(0.64)$ & $70(0.61)$ & $42(0.72)$ & $76(0.68)$ & $36(0.59)$ & $57(0.53)$ & $46(0.88)$ & $92(0.64)$ & $20(0.71)$ \\
\hline $\mathrm{CT}$ & $111(0.21)$ & $55(0.32)$ & $41(0.36)$ & $14(0.24)$ & $33(0.29)$ & $22(0.36)$ & $44(0.41)$ & $6(0.12)$ & $48(0.33)$ & $7(0.25)$ \\
\hline $\mathrm{TT}$ & $7(0.01)$ & $6(0.04)$ & $4(0.03)$ & $2(0.04)$ & $3(0.03)$ & $3(0.05)$ & $6(0.06)$ & $0(0.00)$ & $5(0.03)$ & $1(0.04)$ \\
\hline $\mathrm{CT}+\mathrm{TT}$ & $118(0.22)$ & $61(0.36)$ & $45(0.39)$ & $16(0.28)$ & $36(0.32)$ & $25(0.41)$ & $50(0.47)$ & $6(0.12)$ & $53(0.36)$ & $8(0.29)$ \\
\hline \multirow{3}{*}{\multicolumn{2}{|c|}{$\begin{array}{l}\text { (b) Statistical evaluation } \\
\text { RA patients group vs } \\
\text { controls }\end{array}$}} & \multirow{3}{*}{\multicolumn{2}{|c|}{$\begin{array}{l}\text { Alleles } \\
\mathrm{P} \text { value }\end{array}$}} & \multirow{3}{*}{\multicolumn{2}{|c|}{$\begin{array}{l}\text { Odds ratio }(95 \% \mathrm{Cl}) \\
\text { for } 1858 \mathrm{~T} \text { allele }\end{array}$}} & \multirow{3}{*}{\multicolumn{2}{|c|}{$\begin{array}{l}\text { All genotypes } \\
\mathrm{P} \text { value }\end{array}$}} & & \multirow{3}{*}{\multicolumn{2}{|c|}{$\begin{array}{l}\text { Odds ratio (95\% Cl) } \\
\text { for } C T+T T \text { genotypes }\end{array}$}} \\
\hline & & & & & & & & $C T+T T$ vs $C C$ & & \\
\hline & & & & & & & & $\mathrm{P}$ value & & \\
\hline \multicolumn{2}{|l|}{ All cases } & \multicolumn{2}{|r|}{0.0004} & \multicolumn{2}{|c|}{$1.8(1.33-2.55)$} & \multicolumn{2}{|l|}{0.0009} & 0.0006 & \multicolumn{2}{|c|}{$1.96(1.35-2.84)$} \\
\hline \multicolumn{2}{|c|}{ Limited to joints } & \multicolumn{2}{|r|}{0.0002} & \multicolumn{2}{|c|}{$2.08(1.44-3.00)$} & \multicolumn{2}{|l|}{0.0003} & 0.0002 & \\
\hline \multicolumn{2}{|c|}{$\begin{array}{l}\text { Extra-articular } \\
\text { manifestations }\end{array}$} & \multicolumn{2}{|r|}{0.23} & \multicolumn{2}{|c|}{-} & \multicolumn{2}{|l|}{0.33} & 0.32 & \multicolumn{2}{|c|}{$2.32(1.51-3.55)$} \\
\hline \multirow{2}{*}{\multicolumn{2}{|c|}{$\begin{array}{l}\text { RF+ } \\
\text { RF- }\end{array}$}} & \multicolumn{2}{|r|}{0.019} & \multicolumn{2}{|c|}{$1.6(1.10-2.40)$} & \multicolumn{2}{|l|}{0.05} & 0.02 & \multicolumn{2}{|c|}{$1.71(1.09-2.67)$} \\
\hline & & \multicolumn{2}{|c|}{0.0008} & \multicolumn{2}{|c|}{$2.29(1.44-3.63)$} & \multicolumn{2}{|l|}{0.001} & 0.001 & \multicolumn{2}{|c|}{$2.50(1.44-4.33)$} \\
\hline \multicolumn{2}{|l|}{$\begin{array}{l}\text { RF- } \\
\text { Anti-CCP+ }\end{array}$} & & 0.0001 & $5.79(2.4-13$ & & $<0.0001$ & & $<0.0001$ & $3.2(2$ & $-4.9)$ \\
\hline Anti-CCP- & & & 0.10 & - & & 0.20 & & 0.11 & & - \\
\hline $\mathrm{ED}+$ & & & 0.0003 & $1.92(1.34-2$ & 71) & 0.0008 & & 0.005 & 2.07 & $40-3.10)$ \\
\hline ED- & & & 0.29 & - & & 0.49 & & 0.36 & & - \\
\hline
\end{tabular}


Table 3 PTPN22 1858C $>$ T polymorphism in allergic asthma

(a) Allele and genotype frequencies

\begin{tabular}{|c|c|c|c|c|c|c|}
\hline PTPN22 1858C $>T$ & $\begin{array}{l}\text { Controls } \\
(\mathrm{N}=543)\end{array}$ & $\begin{array}{l}\text { All cases } \\
(\mathrm{N}=198)\end{array}$ & $\begin{array}{l}\text { Asthma I } \\
(\mathrm{N}=54)\end{array}$ & $\begin{array}{l}\text { Asthma II } \\
(\mathrm{N}=52)\end{array}$ & $\begin{array}{c}\text { Asthma I+II } \\
(\mathrm{N}=106)\end{array}$ & $\begin{array}{c}\text { Asthma III } \\
(\mathrm{N}=92)\end{array}$ \\
\hline \multicolumn{7}{|l|}{ Alleles } \\
\hline C & $961(0.88)$ & $351(0.89)$ & $92(0.85)$ & $94(0.90)$ & $186(0.88)$ & $165(0.90)$ \\
\hline $\mathrm{T}$ & $125(0.12)$ & $45(0.11)$ & $16(0.15)$ & $10(0.10)$ & $26(0.12)$ & $19(0.10)$ \\
\hline \multicolumn{7}{|l|}{ Genotypes } \\
\hline CC & $425(0.78)$ & $156(0.79)$ & $39(0.72)$ & $43(0.83)$ & $82(0.77)$ & $74(0.80)$ \\
\hline $\mathrm{CT}$ & $111(0.21)$ & $39(0.20)$ & $14(0.26)$ & $8(0.15)$ & $22(0.21)$ & $17(0.19)$ \\
\hline Tा & $7(0.01)$ & $3(0.01)$ & $1(0.02)$ & $1(0.02)$ & $2(0.02)$ & $1(0.01)$ \\
\hline $\mathrm{CT}+\mathrm{TT}$ & $118(0.22)$ & $42(0.21)$ & $15(0.28)$ & $9(0.17)$ & $24(0.23)$ & $18(0.20)$ \\
\hline \multicolumn{7}{|l|}{ (b) Statistical evaluation } \\
\hline Allergic asthma patients group vs & Alleles & All genotypes & $C T+T T$ vs $C C$ & & & \\
\hline controls & $\mathrm{P}$ value & $\overrightarrow{\mathrm{P}}$ value & $\mathrm{P}$ value & & & \\
\hline All cases & 1.0 & 0.95 & 0.92 & & & \\
\hline Asthma I & 0.35 & 0.59 & 0.31 & & & \\
\hline Asthma II & 0.63 & 0.65 & 0.59 & & & \\
\hline Asthma I+II & 0.73 & 0.89 & 0.90 & & & \\
\hline Asthma III & 0.71 & 0.89 & 0.8 & & & \\
\hline
\end{tabular}

association. This result is in accord with that of Orozco et $a l^{7}$ who observed higher frequency of extra-articular disease among 1858T-negative Spanish patients. Finally, we found much stronger association of $1858 \mathrm{~T}$ with RF-negative than with RF-positive RA, in contrast to some other studies. ${ }^{8,17}$ However, many laboratories ${ }^{6,7,18}$ did not observe substantial differences between $1858 \mathrm{~T}$ frequencies in RF-positive and RF-negative RA patients, and Dieudé et $a l^{5}$ found $1858 \mathrm{~T}-\mathrm{RF}$ association in transmission disequilibrium test, but not in affected sib-pair test. Therefore, the restriction of the association of $1858 \mathrm{~T}$ with RF-positive RA is still controversial and requires further study. On the other hand, we observed very strong association of $1858 \mathrm{~T}$ allele with the presence of aCCP antibodies, in accord with recent findings of Plenge et $\mathrm{al}^{19}$ and Johansson et al. ${ }^{20}$

The reason for 1858T allele associations with some but not with other clinical manifestations of RA, is not clear. This missense SNP (R620W) abolishes the interaction of LYP with Csk kinase and was originally assumed to cause insufficient inhibition of T-cell activation, leading to autoaggression. ${ }^{3}$ However, it was demonstrated subsequently that $620 \mathrm{~W}$ substitution actually results in rather stronger inhibitory function independent of Csk. ${ }^{21}$ This gain of function might raise the threshold of immature thymocyte activation, leading to insufficient elimination of autoreactive clones and, in consequence, autoimmune disease. ${ }^{1}$ Interestingly, LYP amounts in natural killer (NK) cells are higher than in T lymphocytes but LYP function in these cells is unknown. ${ }^{2}$ Not only T lymphocytes, but also NK cells play a role in RA pathology, ${ }^{22,23}$ although their contribution to different clinical manifestations of this disease is not known. It is therefore conceivable that associations of $1858 \mathrm{~T}$ allele of PTPN22 with some severe manifestations of RA such as erosive disease but not with others (eg, extra-articular disease) may result from contribution of different immunocyte subpopulations (Th1, Th2, NK, and so on).

Although multiple other SNPs were described in PTPN22 gene, most of them did not affect susceptibility to RA, with only one or two approaching the effect of $1858 \mathrm{C}>\mathrm{T}^{16}{ }^{16} \mathrm{It}$ will be interesting, then, to check whether their associations can be reproduced in our sample.

In the light of the strong contribution of $1858 \mathrm{C}>\mathrm{T}$ SNP to RA and other autoimmune diseases, ${ }^{2}$ we also expected to find its association with allergic asthma, for two reasons: (i) the effect of $1858 \mathrm{~T}$ substitution on T-cell activity, which is exaggerated in allergy; and (ii) the involvement of antibodies (autoantibodies) to pathology of these autoimmune diseases, which exhibit $1858 \mathrm{C}>\mathrm{T}$ associations, and also the involvement of antibodies (of $\operatorname{IgE}$ class) to pathology of allergy. To our surprise, 1858C $>$ T allele and genotype frequencies were virtually identical in allergic asthmatic patients and controls. The explanation may be found in substantial differences between autoimmune and allergic diseases: although antibodies are involved in both types of disease, they differ both in immunoglobulin class and specificity (anti-self $v s$ anti-allergen). In addition, even the association of $1858 \mathrm{C}>\mathrm{T}$ SNP with autoantibodymediated diseases is not absolute; for example, systemic scleroderma, characterized by many autoantibodies, ${ }^{24}$ is not associated with it. ${ }^{25}$

In summary, we found strong associations of $1858 \mathrm{C}>\mathrm{T}$ SNP with RA and its several clinical manifestations. We also performed, for the first time, a study on the distribution of $1858 \mathrm{C}>\mathrm{T}$ in allergic asthma showing no association of this SNP with susceptibility to asthma or with its severity. 


\section{Acknowledgements}

This work was supported by the Polish Ministry of Science and High Education Grants No. 2 P05A 06928 and No. 2 P05B 04827 and by the Ludwik Hirszfeld Institute of Immunology and Experimental Therapy Grant No. 14/2007.

\section{References}

1 Bottini N, Vang T, Cucca F, Mustelin T: Role of PTPN22 in type 1 diabetes and other autoimmune diseases. Semin Immunol 2006; 18: 207-213.

2 Gregersen PK, Lee H-S, Batliwalla F, Begovich AB: PTPN22: setting thresholds for autoimmunity. Semin Immunol 2006; 18: 214-223.

3 Bottini N, Musumeci L, Alonso A et al: A functional variant of lymphoid tyrosine phosphatase is associated with type I diabetes. Nat Genet 2004; 36: 337-338.

4 Begovich AB, Carlton VE, Honigberg LA et al: A missense singlenucleotide polymorphism in a gene encoding a protein tyrosine phosphatase (PTPN22) is associated with rheumatoid arthritis. Am J Hum Genet 2004; 75: 330-337.

5 Dieudé P, Garnier S, Michou L et al: Rheumatoid arthritis seropositive for the rheumatoid factor is linked to the protein tyrosine phosphatase nonreceptor 22-620W allele. Arthritis Res Ther 2005; 7: R1200-R1207.

6 Hinks A, Barton A, John S et al: Association between the PTPN22 gene and rheumatoid arthritis and juvenile idiopathic arthritis in a UK population. Further support that PTPN22 is an autoimmunity gene. Arthritis Rheum 2005; 52: 1694-1699.

7 Orozco G, Sanchez E, Gonzalez-Gay MA et al: Association of a functional single-nucleotide polymorphism of PTPN22, encoding lymphoid protein phosphatase, with rheumatoid arthritis and systemic lupus erythematosus. Arthritis Rheum 2005; 52: 219-224.

8 Michou L, Lasbleiz S, Rat A-C et al: Linkage proof for PTPN22, a rheumatoid arthritis susceptibility gene and a human autoimmunity gene. Proc Natl Acad Sci USA 2007; 104: 1649-1654.

9 Rueda B, Núñez C, Orozco G et al: C1858T functional variant of PTPN22 gene is not associated with celiac disease genetic predisposition. Hum Immunol 2005; 66: 848-852.

10 Rottem M, Shoenfeld Y: Asthma as a paradigm for autoimmune disease. Int Arch Allergy Immunol 2003; 132: 210-214.

11 Pawlik A, Ostanek L, Brzosko I, Masiuk M, Machaliński B, Gawrońska-Szklarz B: The expansion of $\mathrm{CD} 4^{+} \mathrm{CD} 28^{-} \mathrm{T}$ cells in patients with rheumatoid arthritis. Arthritis Res Ther 2003; 5: R210-R213.

12 NHLBI/WHO Workshop Report: Global strategy for asthma management and prevention. NIH Publication no. 02-3659, February 2002.
13 Jasek M, Łuszczek W, Obojski A et al: Distribution of CTLA-4 polymorphisms in allergic asthma. Int Arch Allergy Immunol 2006; 141: $223-229$.

14 Skórka A, Bednarczuk T, Bar-Andziak E, Nauman J, Płoski R: Lymphoid tyrosine phosphatase (PTPN22/LYP) variant and Graves' disease in a Polish population: association and gene dose-dependent correlation with age at onset. Clin Endocrinol 2005; 62: 679-682.

15 Pawlik A, Ostanek L, Brzosko I, Gawrońska-Szklarz B, Brzosko M, Dąbrowska-Żamojcin E: Increased genotype frequency of $\mathrm{N}$ acetylase 2 slow acetylation in patients with rheumatoid arthritis. Clin Pharmacol Ther 2002; 72: 319-325.

16 Carlton VE, Hu X, Chokkalingam AP et al: PTPN22 genetic variation: evidence for multiple variants associated with rheumatoid arthritis. Am J Hum Genet 2005; 77: 567-581.

17 Harrison P, Pointon JJ, Farrar C, Brown MA, Wordsworth BP. Effects of PTPN22 C1858T polymorphism on susceptibility and clinical characteristics of British Caucasian rheumatoid arthritis patients. Rheumatology 2006; 45: 1009-1011.

18 van Oene M, Wintle RF, Liu X et al: Association of the lymphoid tyrosine phosphatase R620W variant with rheumatoid arthritis, but not with Crohn's disease, in Canadian populations. Arthritis Rheum 2005; 52: 1993-1998.

19 Plenge RM, Padyukov L, Remmers EF et al: Replication of putative candidate-gene associations with rheumatoid arthritis in $>4,000$ samples from North America and Sweden: association of susceptibility with PTPN22, CTLA-4 and PAD14. Am J Hum Genet 2005; 77: 1044-1060.

20 Johansson M, Ärlestig L, Hallmans G, Rantapää-Dahlqvist S: PTPN22 polymorphism and anti-cyclic citrullinated peptide antibodies in combination strongly predicts future onset of rheumatoid arthritis and has a specificity of $100 \%$ for the disease. Arthritis Res Ther 2006; 8: R19.

21 Vang T, Congia M, Macis MD et al: Autoimmune-associated lymphoid tyrosine phosphatase is a gain-of-function variant. Nat Genet 2005; 37: 1317-1319.

22 Dalbeth N, Gundle R, Davies RJO, Lee YCG, McMichael AJ, Callan MFC: CD56 $6^{\text {bright }}$ NK cells are enriched at inflammatory sites and can engage with monocytes in a reciprocal program of activation. J Immunol 2004; 173: 6418-6426.

23 Falgarone G, Jaen O, Boissier MC: Role for innate immunity in rheumatoid arthritis. Joint Bone Spine 2005; 72: 17-25.

24 Arnett FC: Is scleroderma an autoantibody mediated disease? Curr Opin Rheumatol 2006; 18: 579-581.

25 Wipff J, Allanore Y, Kahan A et al: Lack of association between the protein tyrosine phosphatase non-receptor 22 (PTPN22)*620W allele and systemic sclerosis in the French Caucasian population. Ann Rheum Dis 2006; 65: 1230-1232. 